\title{
Arielismo, politica e religião nos escritos de José Enrique Rodó sobre os Estados Unidos
}

\author{
Fabio Muruci dos Santos ${ }^{1}$
}

\begin{abstract}
Resumo: O ensaio Ariel, publicado em 1900 pelo filósofo uruguaio José Enrique Rodó, foi uma das obras mais influentes do pensamento hispano-americano. O texto apresenta uma crítica aos reformadores influenciados por ideias evolucionistas e utilitaristas que consideravam os Estados Unidos como um modelo a ser copiado pelos países latinoamericanos e que consideravam o protestantismo como um dos fatores principais para $o$ sucesso econômico do país. Contra essas filosofias modernizadoras, Rodó apresenta uma defesa dos valores católicos latinos, os quais valorizariam a importância da estética e do ócio criativo, diferentemente do foco puritano na disciplina. Nossa proposta é que um dos objetivos de Ariel é apresentar uma crítica de diversos aspectos da religiosidade estadunidense, entre eles a influência puritana e as narrativas edenistas, repudiando os EUA como um modelo de novos caminhos para a humanidade. Ao contrário, seria uma sociedade ameaçada pela estagnação trazida por uma educação homogeneizadora e um foco demasiado no igualitarismo.
\end{abstract}

Palavras-Chave: Arielismo; edenismo; puritanismo.

\section{Arielism, politics and religion in José Enrique Rodó's writings on United States}

\begin{abstract}
The essay Ariel, published in 1900 by the Uruguayan philosopher José Enrique Rodó, was one of the most influential works of Hispanic-American thought. The text criticizes reformers influenced by evolutionist and utilitarian ideas that considered the United States as a model to be copied by Latin American countries and regarded Protestantism as one of the main factors for the economic success of the country. Against these modernizing philosophies, Rodó defends Latin Catholic values, which would appreciate the importance of aesthetics and creative leisure, differently from the Puritan focus on discipline. Our proposal is that one of Ariel's goals is to present a critique of several aspects of American religiosity, among them the Puritan influence and the Edenic narratives, repudiating the USA as a model of new paths for humanity. On the contrary, it would be a society threatened by the stagnation brought by homogenizing education and a focus on egalitarianism.
\end{abstract}

Keywords: Arielism; edenism; puritanism.

Artigo recebido em: 28/01/2021

Artigo aprovado para publicação em: 30/03/2021

\footnotetext{
1 Doutor em História pela UFRJ. Professor do Departamento de História da UFES. Pesquisa em andamento: "Progresso e Nostalgia nas Crônicas Urbanas de Machado de Assis, Lima Barreto e José Martí”. E-mail: fmuruci@yahoo.com.br.
} 
Em seu influente ensaio de 1900, Ariel, o filósofo uruguaio José Enrique Rodó procurava fazer um alerta contra os entusiastas do modelo norte-americano, que queriam "uma América deslatinizada por vontade própria, sem a extorsão da conquista e logo regenerada à imagem e semelhança do arquétipo do Norte" (RODÓ, 1991, p. 70). A guerra de independência de Cuba, encerrada em 1898 com a decisiva intervenção norte-americana, havia marcado toda uma geração de intelectuais hispano-americanos. Em vários países do continente, o temor de que a emergente potência do norte pudesse ameaçar a autonomia dos países da região estimulou uma intensa produção de ensaios sobre as relações entre as duas Américas, seus respectivos processos históricos e os fundamentos culturais de cada uma. Mas a discussão não foi apenas uma reação circunstancial ao expansionismo norte-americano. Ela já estava em andamento como parte dos esforços para a superação do quadro de conflito endêmico que havia dominado boa parte da América Espanhola após as independências. Tratava-se de estabelecer modelos de ordem social e política que substituíssem o controle dos caudilhos sobre a vida republicana local.

A república norte-americana poderia fornecer modelos nesse sentido, desde que isso não implicasse uma ameaça à soberania continental. Tal dilema deu aos ensaios sobre a identidade americana, na virada para o século $\mathrm{XX}$, uma característica ambiguidade em seu tratamento da vida política e social nos Estados Unidos. Na América Espanhola, o tema foi particularmente impulsionado pela publicação de Ariel, que alcançou projeção em todo o continente e se tornou obra de referência para várias gerações de intelectuais hispânicos, até que sua aceitação viesse a cair após a Segunda Guerra Mundial. Luis Alberto Sanchez informa, como um testemunho pessoal, que toda a geração de estudantes à qual pertenceu foi formada por mestres arielistas nas universidades hispano-americanas dos anos 1920 a 1940 (SANCHEZ, 1941). Um dos traços notáveis da recepção do "arielismo", como veio a ser chamado, foi sua aglutinação com várias abordagens distintas da identidade ibero-americana, desde a reforma universitária de Córdoba, na Argentina de 1918, até aos intelectuais do período pós-revolucionário mexicano. 
A difusão do arielismo acompanhou de perto a onda de pensamento nacionalista que se estendeu pelo continente nas primeiras décadas do século XX. Tentativas de consolidação do Estado-nação na América Ibérica haviam alcançado pouco resultado após as lutas de independência, diante do duradouro fracasso das elites criollas civis em elaborar um imaginário nacional eficiente para superar as diversas fidelidades regionais geradas pela própria luta. As últimas décadas do século XIX foram um momento de redescoberta, ou melhor, de reinvenção das esperanças iniciais na promessa americana. Naquele momento, um renovado interesse pelo pensamento "idealista" europeu, após a longa influência de teorias evolucionistas e positivistas, resultou nas mais diversas propostas para a regeneração das nacionalidades, agora não mais vistas como ameaçadas pelos vícios da própria formação americana, como havia sustentado Domingo Sarmiento em Facundo, mas sim pelo cosmopolitismo e o materialismo, frequentemente identificados com capitais em processo de modernização, como o Rio de Janeiro e Buenos Aires. Ao mesmo tempo, procuravam desenvolver mecanismos que integrassem os fragmentos de países deixados pelas lutas civis do século anterior.

Os vários projetos regeneracionistas tinham alguns pontos em comum, como a defesa de modelos de educação que estimulassem o sentimento nacional e a recuperação da memória dos heróis pátrios. Em praticamente todos os casos, o tema central era a necessidade de constituição de comunidades nacionais. Mas as vias políticas disponíveis para estabilizar essas comunidades não alcançavam unanimidade. Dentro do campo aqui enfocado, os projetos iam desde a afirmação de regimes liberais constitucionais mais efetivos até a expectativa por líderes fortes, inspirados na personagem permanentemente reelaborada de Simón Bolívar, capazes de submeter os caciques locais. Em alguns casos, surgiram mesmo esperanças sincréticas por ditadores personalistas com sentimento nacional, uma variante do caudilhismo sem os traços anárquicos anteriores, soluções duramente criticadas pelos adeptos da institucionalização do liberalismo (DEVEZ VALDÉS, 2000). Dessa forma, apesar de algumas bases em comum, não podemos falar de um arielismo homogêneo, mas sim de uma série de apropriações ecléticas, que frequentemente resultavam em conclusões muito diferentes.

Ariel, em princípio, é um manifesto em defesa da especificidade histórica da cultura latino-americana contra a ameaça que os Estados Unidos começaram a 
representar após os eventos de 1898. A derrota espanhola estimulou a produção de diagnósticos sobre a condição de 'atraso', expressão aplicada com frequência para sociedades localizadas nas margens do capitalismo moderno e que sentiam a intensa angústia de um acesso incompleto à modernidade. Nas análises apoiadas em teorias evolucionistas, a formação católica era especialmente apontada como uma das raízes do atraso sócio-econômico e intelectual das regiões de língua espanhola. A ética protestante, ao contrário, teria estimulado a disciplina e a dedicação ao trabalho, atraindo a simpatia de muitos modernizadores latino-americanos, que viram nos Estados Unidos uma inspiração para a reconstrução não só econômica como também moral de seus países. Em grande parte, Ariel é uma resposta crítica a tais abordagens.

Rodó argumenta que os Estados Unidos, mesmo querendo, dificilmente poderiam ocupar uma posição inspiradora porque careceriam dos meios adequados para atrair a afeição de outros povos:

Eles pretenderam rever o Gêneses para ocupar essa primeira página. Mas, além da relativa insuficiência do papel que lhes é dado reinvidicar na educação da humanidade, seu próprio caráter lhes nega a possibilidade de hegemonia. A natureza não lhes concedeu o gênio da propaganda nem a vocação apostólica. Carecem desse dom superior de amabilidade - no sentido elevado -, desse extraordinário poder de simpatia com que as raças encarregadas de uma incumbência providencial de educação sabem dar à sua cultura algo semelhante à beleza da Hélade clássica, na qual todos julgavam reconhecer um traço próprio" (RODÓ, 1991, p. 91).

Aqui argumentaremos que Ariel pode ser lido não apenas como um manifesto anti-imperialista, mas, igualmente, como uma análise crítica de diversos aspectos da religiosidade estadunidense e como estes influenciaram a constituição daquela sociedade. Entre os pontos importantes estavam as raízes puritanas e as mitologias "edênicas" Um dos aspectos pouco comentados pela recepção crítica de Ariel são as referências no texto às auto-representações da cultura norte-americana, especialmente sua mitologia edênica, da qual procurava refutar um de seus aspectos principais: o fator inaugural (novo Éden). A representação da America gerada a partir do simbolismo puritano nos Estados Unidos foi, em grande parte, construída em torno da tensão entre as imagens de Garden e Wilderness. No simbolismo bíblico puritano, de profunda influência no pensamento do século XIX, as terras virgens da América poderiam 
oferecer dois caminhos opostos. Na doutrina puritana mais ortodoxa, a America é identificada como a wilderness, o ermo não cultivado onde Adão, após a queda, deve trabalhar arduamente para purgar seus erros. A estrita observância das regras e a rejeição dos prazeres mundanos e da carne são imposições para quem pretende criar a cidade santa no Novo Mundo. Um continente virgem aparece como propício para o exercício do autocontrole. Em uma versão mais laica do século XVIII, como a de Benjamim Franklin, a disciplina do tempo e do trabalho contra o caos das paixões, representação humana da wilderness, aparece como caminho para o sucesso comercial, tornando visível o cumprimento de uma vocação designada pela Providência (HOWE, 1997).

Essa interpretação foi questionada por outra leitura do mesmo simbolismo que, a partir do século XVIII, apresentava a América como o jardim recuperado, uma nova chance para o homem após o desastre da primeira tentativa. A Europa, identificada com monarquia, feudalismo, obscurantismo religioso e outras mazelas do Velho Mundo se tornava uma terra conspurcada pelo passado, onde a liberdade e criatividade humanas permaneciam amarradas pelas instituições. Na América, ao contrário, Adão renasceria antes do pecado original, despido do fardo de um erro primeiro, agora identificado com as convenções artificiais. Recupera então sua nudez para construir o Novo Mundo. O Adão americano é uma expressão na crença do poder do individualismo como estimulador das energias criativas do homem. Essa personagem recebeu inumeráveis elaborações literárias durante todo o século XIX, quando o Adão americano aparece como um indivíduo emancipado da história, tendo como principal qualidade a autoconfiança nos seus próprios recursos. Esse homem redimido seria a expressão individual de um acordo maior (Covenant) em que os norte-americanos, como povo escolhido pela Providência, estariam livres dos horrores da mudança e do turbilhão contínuo da história que atormentavam a Europa, protegidos no Jardim recuperado, onde poderiam viver em uma harmonia estável e eterna com a Natureza. Seu estado de inocência reconquistada seria demonstrado pelo fluxo progressivo e natural de sua história (NOBLE, 1968).

Rodó não deixa de apontar algumas realizações históricas positivas da cultura norte-americana. Valoriza a importância que deram ao trabalho, sua preocupação com a 
educação popular e o espírito de virtude republicana que teria presidido a fundação política do país. Mas essas qualidades do passado estariam sofrendo um forte processo de corrosão na nova América industrial do pós-Guerra Civil. Uma sociedade orientada por filosofias utilitaristas, desejo descontrolado de enriquecimento material e corrupção política. Em sua abordagem dos Estados Unidos de sua época, a poderosa presença do utilitarismo na vida norte-americana teria raízes mais longínquas que a ascensão da plutocracia industrial do fim do século XIX. Não deixa de haver ambiguidade em seus comentários sobre esse ponto quando afirma que a ética puritana ainda é um dos fatores que "segura, entre as asperezas do tumulto utilitário, a rédea firme do senso moral" (RODÓ, 1991, p. 77). As análises mais extensas, porém, tendem a seguir caminho oposto, identificando o puritanismo como uma das raízes da atitude utilitária que dominaria a sociedade norte-americana. Nessa leitura, os momentos centrais da história anglo-americana teriam sido aqueles que direcionaram a vida inglesa para o crescente predomínio do espírito mercantil em prejuízo de suas origens mais épicas:

O espírito inglês, sob o áspero córtex do utilitarismo, sob a indiferença mercantil, sob a severidade puritana, indubitavelmente esconde uma virtualidade poética seleta e um profundo manancial de sensibilidade, o qual revela, na impressão de Taine, que o fundo primitivo, o fundo germânico daquela raça, logo modificada pela pressão da conquista e pelo hábito da atividade comercial, foi uma extraordinária exaltação do sentimento. (RODÓ, 1991, p. 82).

Rodó relacionava intimamente a ascensão da ética protestante com a formação de hábitos propícios para a consolidação do capitalismo mercantil e lamentava profundamente que tal aliança tenha imperado em uma cultura inglesa que, até então, havia sido um manancial de idealismo, alimentado pela mitologia de origem germânica. Fragmentos daquela cultura desaparecida ainda apareceriam na qualidade da produção poética inglesa, mas estariam definitivamente perdidos ao serem transplantados para a América, onde somente o lado mais comercial da civilização inglesa encontrou espaço:

Dir-se-ia que o positivismo do gênio da Metrópole, ao se transmitir a seus filhos emancipados da América, sofreu uma destilação que o priva de todos os elementos de idealidade que o temperavam, reduzindo-o, na realidade, à crueza que, nos exageros da paixão e da sátira, foi possível atribuir ao positivismo da Inglaterra. (RODÓ, 1991, p. 81). 
Discordando da história do puritanismo de Macaulay, defendia que "como nem a liberdade nem a virtude precisam ser guardadas em caixas de chumbo, para a educação da liberdade sempre valerão, muito mais do que todos os rigores dos ascetas e puritanos, a moral harmoniosa de Platão, o movimento delicado e elegante com que a mão de Atenas ergueu a taça da vida para levá-la aos lábios” (RODÓ, 1991, p. 43). Já em sua origem, o puritanismo seria um momento fundador repressivo fundamental para a conformação da personalidade coletiva anglo-americana:

O puritanismo, que perseguiu toda e qualquer beleza e seleção intelectual, que cobriu indignado a casta nudez das estátuas, que professou a ostentação da fealdade nas maneiras, nos trajes e nos discursos - a seita triste que, impondo seu espírito a partir do Parlamento inglês, mandou extinguir as festas que manifestassem alegria e cortar as árvores que dessem flores -, estendeu junto à virtude, ao divorciá-la do sentimento do belo, uma sombra de morte que a Inglaterra ainda não conjurou de todo, e que perdura nas manifestações menos agradáveis de sua religiosidade e de seus costumes. (RODÓ, 1991, p. 43).

O princípio do self-control em Rodó aparece como um elemento empobrecedor do espírito criativo, especialmente o estético: "A idealidade do belo não arrebata o descendente dos austeros puritanos". (RODÓ, 1991, p. 84). A repressão da criação estética em favor da disciplina produtiva, especialmente quando esta última é direcionada exclusivamente para o desejo aquisitivo, teria criado nos Estados Unidos uma personalidade coletiva repetitiva e unidimensional, incapaz de abrir espaço para a exploração das diversas faculdades que compõem o espírito humano.

A marca profunda do puritanismo na cultura anglo-americana teria sido fundamental para encaminhar a tendência para a especialização que caracterizaria a organização do trabalho nas sociedades de língua inglesa. Uma das consequências mais perversas desse processo seria o predomínio da concepção utilitária no campo religioso: "A religiosidade americana, como derivação extrema da inglesa, não é senão uma força auxiliar da legislação penal, que abandonaria seu posto no dia em que fosse possível conferir à moral utilitária a autoridade religiosa que Stuart Mill ambicionava lhe conceder" (RODÓ, 1991, p. 1986). Mas a refutação dessa abordagem utilitária não se faz propriamente em favor de uma demanda de sacralidade, pela qual Rodó demonstrou 
ser pouco interessado. Sua principal conexão estaria com a dimensão estética da religião e sua capacidade de inspiração moral.

Esse quadro permitiu que Rodó questionasse um dos pontos centrais da mitologia norte-americana do século XIX, o da radical novidade do experimento norteamericano e de seu potencial inaugural para um novo mundo livre das mazelas da velha Europa, tema tão importante para Sarmiento e outros liberais dos oitocentos (MURUCI, 2007). A crença de representar uma experiência de organização política absolutamente nova na história humana, a condição de newness, está estreitamente relacionada, na mitologia nacional norte-americana, com o cumprimento de uma missão histórica de libertar o homem da escravidão europeia (BELLAH, 1992). Para Rodó, a ausência de vocação apostólica tornaria totalmente infundadas as pretensões norte-americanas de formarem uma nova matriz para a civilização: “a obra realizada pela perseverante genialidade do ária europeu (...) constitui uma soma com a qual não é possível equacionar a fórmula Washington + Edison" (RODÓ, 1991, p. 91). Diferentemente dos fundamentos anti-estéticos da cultura puritana, o catolicismo latino teria grande capacidade de usar a estética como instrumento de convencimento, apoiada mais na "amabilidade" que na disciplina.

Mas o tema da liderança por meio da 'amabilidade' abrange um escopo mais amplo que o da disputa entre nações pela primazia na condução espiritual e política do mundo, estando presente em toda a concepção rodoniana de reforma. Ela seria a qualidade privilegiada de todos aqueles que pretendem ocupar uma posição apostólica diante dos homens: "É imenso o papel que, na eficácia das revoluções morais, corresponde ao dom de descobrir e revelar a beleza íntima das idéias" (RODÓ, 1991, p. 42). O apóstolo, na concepção cristã inicial, teria uma atenção pela sedução estética que seria ignorada pelos defensores de uma moral normativa, baseada em proibições e autocontrole rígidos. A partir daí, Rodó expõe uma concepção mais ampla sobre as relações entre virtude e estética como forças interdependentes: "Os que exigem que o bem e a verdade se manifestem invariavelmente em formas austeras e severas sempre me parecem amigos traidores do bem e da verdade. A virtude também é um gênero de arte" (RODÓ, 1991, p. 40). 
A percepção e cultivo da beleza são faculdades que expandiriam o potencial de singularização dos indivíduos, em oposição ao universo normativo, que estimula a repetitividade e homogeneização. Na percepção de Rodó, a homogeneidade seria um limitador das singularidades criadoras, princípio que aplicava tanto aos indivíduos como às sociedades: "faz parte dos deveres humanos que cada um de nós cuide e conserve zelosamente a originalidade de seu caráter pessoal, o que nele existe que o diferencie e determine" (RODÓ, 1991, p. 72). E somente o estímulo da singularidade poderia produzir os líderes capazes de servir de referência para a sociedade e legitimar uma ordem política democrática seletiva baseada no consentimento. Nesse sentido, seu modelo de exemplaridade seria oferecido por líderes dotados de virtudes e habilidades notáveis, mais perto do "heroísmo", o tipo de originalidade que uma sociedade homogênea de massas, como os Estados Unidos, seria incapaz de produzir:

\footnotetext{
A oposição entre o regime da democracia e a alta vida do espírito é uma realidade fatal quando esse regime significa o desconhecimento das desigualdades legítimas e a substituição da fé no heroísmo - na acepção de Carlyle - por uma concepção mecânica de governo. (RODÓ, 1991, p. 55).
}

A padronização da sociedade norte-americana, que já estaria anunciada desde o seu momento fundador, teria sido ainda mais acentuada pela industrialização, que subordinou toda a sociedade aos princípios da atividade mecânica, como o operário "que, com a divisão do trabalho na fábrica, é obrigado a consumir todas as energias de sua vida na invariável operação de um detalhe mecânico" (RODÓ, 1991, p. 29). O ritmo industrial bloqueava a possibilidade do tempo ocioso, o qual seria o verdadeiro espaço para o exercício da virtude:

Pensar, sonhar, admirar: tais são os nomes dos etéreos visitantes da minha cela. Os antigos os classificavam dentro de sua nobre concepção do ócio, que consideravam como o mais elevado emprego de uma existência verdadeiramente racional, identificando-o com a liberdade do pensamento emancipado de todo jugo ignóbil. O ócio nobre era o investimento de tempo que contrapunham, como expressão da vida superior, à atividade econômica. (RODÓ, 1991, p. 36).

Não é à toa que Rodó cita com aprovação as críticas feitas por Herbert Spencer aos Estados Unidos durante sua viagem ao país. A escolha de Spencer é estratégica se 
lembrarmos que ele costumava ser lido na América Ibérica (e não só aqui) como ideólogo do competitivismo e da sociedade industrial. Mas os adversários do utilitarismo perceberam que havia também um outro Spencer, que nos últimos momentos de sua vida se mostrava cada vez mais decepcionado com os rumos da sociedade industrial e com a crescente onda imperialista que ameaçava submergir o mundo na barbárie militar (BANNISTER, 1979). Um dos fracassos das sociedades industriais seria exatamente a sua incapacidade de propiciar um modelo de educação que contemplasse todas as faculdades do indivíduo, uma crítica perfeitamente assimilável pelo ideário dos arielistas. Assim, Spencer criticou o regime de trabalho industrial e a obsessão pelo ganho como ameaças ao futuro da democracia norteamericana por transferir o controle da política aos bosses, donos da imprensa marrom e de currais eleitorais. A crítica spenceriana ao utilitarismo se aproximava muito da própria linguagem rodoniana: "O uso mais fundamental do conhecimento é estabelecer um padrão de conduta que torne a vida completa, qualquer que seja a circunstância. Qualquer outro uso do conhecimento é secundário" (SPENCER, 1973, p. 32). O Spencer selecionado por Rodó recusava a concepção utilitarista do trabalho como fim último da vida e pregava o esforço como preparação para os momentos de fruição e criatividade, lugar de realização da completude humana. Desse ponto de vista, demandava dos norte-americanos "uma revisão no seu ideal de vida" (SPENCER, 1973, p. 32).

Rodó utilizava uma clara distinção entre dois modelos de educação, definindo qual deles deveria servir como matriz para o estímulo do civismo e das virtudes desinteressadas, como argumenta em seus texto De la enseñanza constitucional y cívica en los estudios secundários:

Existe um critério utilitário inglês que subordina o objetivo da educação aos interesses práticos ou positivos da vida - à utilidade, em uma palavra -, proscrevendo ou relegando ao nível menos importante tudo o que com ela não se relacione, e há um critério, que poderíamos chamar clássico, segundo o qual a educação deve se propor desinteressadamente a estimular o desenvolvimento integral e harmônico das faculdades humanas. (RODÓ, 1967 , p. 1404). 
Rodó teve o cuidado de discernir a exata linhagem do positivismo iberoamericano ao qual admirava, que não deveria ser confundido com o positivismo dos modernizadores do século XIX, mas sim uma abordagem positivista de vertente católica, que veio a marcar diversas correntes espiritualistas latino-americanas posteriores. Uma das suas características foi a exigência de uma solidariedade iberoamericana baseada na herança comum do idealismo católico ibérico. Em Rumbos Nuevos, Rodó apontou:

O sentimento idealista e generoso que comtianos como Lagarrigue instilaram em sua predicação, mais nobremente inspirado do que bem compreendido e eficaz, não caracteriza a índole do positivismo que chegou a se propagar e divulgar em nossa América. Aqui houve um empirismo utilitarista de muito baixa estatura e capacidade muito mesquinha, como se tivesse sido moldado para bajular, com sua aparente clareza de ideias e com seu limitado alcance moral e social, as mais estreitas inclinações do senso comum. (RODÓ, 1967, p. 519).

Tal positivismo se opunha à versão utilitarista dos admiradores da América do Norte. Presos a um regime de autodisciplina e homogeneidade, os norte-americanos seriam incapazes de encontrar tempo livre para a atividade espiritual desinteressada e criativa, necessária para a plena realização de sua humanidade. Rodó usa um dos santospadroeiros de muitos americanistas na América Ibérica, Benjamim Franklin, como exemplo das perversões do self puritano, quando tornado modelo de comportamento social:

\begin{abstract}
A mais elevada cúspide de sua moral utilitária é a de Franklin: uma filosofia da conducta que encontra seu termo no medíocre da honestidade, na utilidade da prudência, de cujo seio jamais surgirá a santidade nem o heroísmo, e que, capaz de prestar à ciência, nos caminhos normais da vida, apenas o apoio da bengala de macieira com que habitualmente andava seu pregador, não passa de uma frágil madeira quando se trata de galgar as altas encostas. (RODÓ, 1991, p. 86).
\end{abstract}

Franklin foi um dos defensores do interesse como uma possível virtude, e não uma paixão viciosa, desde que estimulasse o desejo de contribuir para o bem comum, como no caso do desejo de "estima" pelo trabalho realizado, e operasse dentro de um modo de vida prudente e honesto. A prudência seria um corretivo para o vício do orgulho, fonte das tiranias personalistas. Os preceitos morais, inclusive os religiosos, 
poderiam alcançar valor por sua utilidade social, mesmo que não estivessem reduzidos a ela. Uma das consequências dessa noção disciplinar da moral é que a intensa valorização do trabalho não é acompanhada por nenhum aproveitamento lúdico do esforço, que permaneceria incapaz de gerar satisfação por si mesmo (HOWE, 1997). Esse elemento utilitário, somado a um modelo de self desapaixonado e autodisciplinar, seria um padrão capaz de dar constância ao mundo, impondo o regime do hábito sobre as paixões, uma característica altamente valorizada pelos defensores setecentistas das "paixões calmas", mas que se tornaria um dos principais alvos da crítica romântica ao caráter mesquinho e sem glória do mundo capitalista (HIRSCHMAN, 1979).

Rodó negava que o fator econômico devesse ter um papel decisivo na seleção de elites. A partir daí, concentrou-se na reflexão sobre os tipos possíveis de liderança e nos valores que lhes confeririam legitimidade no quadro ibero-americano. Essa concentração exclusiva nas qualidades morais, unida à habilidade para despertar a adesão por meio da inspiração moral e estética, traria para a política o tipo de carisma ensinado pelos reformadores morais no modelo do Cristo, um modo de articulação social menos destrutivo que o duro estado de competição pregado pelo darwinismo social:

\footnotetext{
Racionalmente concebida, a democracia admite sempre um imprescritível elemento aristocrático, que consiste em estabelecer a superioridade dos melhores, assegurando-a sobre o consentimento dos associados. Como as aristocracias, ela consagra a distinção de qualidade, mas a resolve em favor das qualidades realmente superiores - a virtude, o caráter, e espírito -, e, sem pretender imobilizá-las em classes constituídas à parte das demais, mantendo para si o execrável privilégio da casta, ela renova sem cessar sua aristocracia dirigente nas fontes vivas do povo, fazendo com que seja aceita pela justiça e pelo amor. Assim (...) ela exclui dessa lei universal da vida, ao sancioná-la na ordem da sociedade, o efeito de dor e humilhação que, nas concorrências da Natureza e das outras organizações sociais, compõe o duro quinhão do vencido. (RODÓ, 1991, p. 64-65).
}

A Natureza rodoniana, em oposição ao competitivismo darwinista, é essencialmente justa e harmônica, distribuindo os talentos de forma proporcional. Caberia aos governantes de uma aristocracia espiritual reconhecer as diferenças imanentes aos homens e abrir caminho para o justo acesso ao poder dos mais brilhantes, mas sem abandonar a compaixão pelo fraco, incorporado ao trabalho histórico a partir 
das artes do convencimento. Rodó não acreditava que a república norte-americana tivesse superado os perigos anunciados por Tocqueville, mas, ao contrário, teria sucumbido definitivamente diante deles. A homogeneidade seria um traço endêmico da vida norte-americana, ainda mais acentuado a partir da industrialização.

De fato, como podemos concluir por seus comentários sobre o ócio aristocrático, os 'barões' da indústria norte-americana seriam os modelos mais adversos possíveis ao seu critério de liderança. Seguindo uma versão idealizada das aristocracias antigas, especialmente a da pólis grega, seria exatamente no momento em que a atividade econômica cessa que o homem teria condições para se entregar ao trabalho pelo bem público, movido apenas pela virtude desinteressada. O dinheiro, na linha do humanismo cívico, não poderia ser critério para diferenciação política (KARAN, 1992). A atividade econômica incessante enfraqueceria as bases da virtude desinteressada, que sustentariam uma república: "a escola da prosperidade material (...) sempre será uma rude prova para a austeridade das repúblicas" (RODÓ, 1991, p. 86). No quadro da vida norte-americana da era industrial, nem os magnatas, envolvidos na competição darwinista brutal, nem os trabalhadores, submetidos ao regime mecânico da linha de produção, poderiam encontrar condições para esse ócio humanizador.

O regime de predomínio absoluto do homo oeconomicus estaria minando a virtude como fator de legitimação da república norte-americana: "O valor cívico, a velha virtude dos Hamilton, é uma lâmina de aço que se oxida, cada dia mais esquecida, entre as teias de aranha das tradições” (RODÓ, 1991, p. 87). Nesse sentido, Rodó conclui que o modelo de República construído pelos Pais Fundadores norte-americanos estaria dando claros sinais de deterioração:

A influência política de uma plutocracia representada pelos todo-poderosos aliados dos trustes, monopolizadores da produção e donos da vida econômica (...) traz à lembrança, de maneira muito provavelmente oportuna, o surgimento da classe enriquecida e soberba que, nos últimos tempos da república romana, foi um dos antecedentes visíveis da ruína da liberdade e da tirania dos Césares. E a preocupação exclusiva com o engrandecimento material - nume daquela civilização - impõe assim a lógica de seus resultados na vida política, bem como em todas as ordens de atividade, conferindo o primeiro lugar ao struggle-for-life ousado e astuto, convertido pela brutal eficácia de seu esforço na suprema personificação da energia nacional, no pretendente à sua representação emersoniana, no personagem reinante de Taine. (RODÓ, 1991, p. 88). 
Rodó aponta várias vezes que os Estados Unidos de fim de século perderam os elementos de nobreza que caracterizaram a Revolução Americana. O resultado mais imediato da mecanização da vida trazida por certos aspectos da modernidade, adversos ao desenvolvimento das singularidades individuais, seria o desgaste das virtudes únicas e exemplares que poderiam servir de referência para uma comunidade republicana: "Enquanto muitos nomes ilustres surgem no período da independência e da organização para representar o pensamento e a vontade daquele povo, Tocqueville, meio século depois, pode observar, referindo-se a eles, que os deuses se vão” (RODÓ, 1991, p. 85). O contexto de mercantilização contemporâneo dá continuidade e radicaliza a emergência de um espírito anti-heróico e homogeneizador estimulado pelo puritanismo, mas, agora, despido da excelência moral que um dia havia sustentado a república. Repercutindo o tema tocquevilliano da homogeneização, Rodó anuncia um fim melancólico para a civilização anglo-americana, acentuando o lado mais pessimista daquela abordagem:

\footnotetext{
Mesmo que o critério moral não descesse abaixo do utilitarismo honrado e comedido de Franklin, o término forçoso - já assinalado pela sagaz observação de Tocqueville - de uma sociedade educada em tal limitação de dever seria certamente, não uma dessas decadências soberbas e magníficas que dão a medida da satânica beleza do mal na dissolução dos impérios, mas sim uma espécie de materialismo pálido e medíocre, e em última instância o torpor de um debilitamento sem brilho pela silenciosa decomposição de todos os recursos da vida moral. (RODÓ, 1991, p. 86).
}

Tocqueville havia descrito como a desagregação do Antigo Regime havia instaurado um quadro de fragmentação das sociedades democratizadas, deslocando os indivíduos autonomizados dos laços tradicionais para o espaço privado. $\mathrm{Na}$ visão de Tocqueville, o individualismo era uma ameaça que estimulava a centralização política, pois minava a tradicional resistência das ordens aristocráticas contra o absolutismo. Em uma sociedade atomizada, não haveria uma prática política educadora que estimulasse a virtude e o interesse pelos temas públicos, o que resultava na mais rápida transferência de poder para o Estado. Os Estados Unidos estiveram provisoriamente livres desse risco 
porque a prática da associação política espontânea nos municípios havia exercido o papel funcional de educar politicamente as massas, trazendo a densidade ética aristocrática para uma sociedade na qual essa categoria social jamais havia existido. Mas uma sociedade de massas não estaria livre de um futuro despotismo político, já que a constante nivelação, geradora de homogeneidade, poderia minar os mecanismos de produção da virtude pública (TOCQUEVILLE, 1998).

O maior dos males da modernidade teria sido a ampla difusão do "espírito comercial", adverso aos valores éticos e ao desejo de distinção da aristocracia, que conferiam a todos os aspectos da vida moderna um caráter de moderação adverso à formação de grandes personalidades. Cabe destacar a importância que a educação teria em Tocqueville para a recuperação dos ideais perdidos no mundo moderno. É essa crítica ao desgaste dos valores da excepcionalidade que Rodó apreende em Tocqueville, mais que o entusiasta do experimento de igualdade norte-americano. Apesar de reconhecer que os norte-americanos "nasceram com a experiência inata da liberdade", Rodó não demonstrava grande entusiasmo pelos resultados do associativismo nos Estados Unidos.

Rodó parecia ter privilegiado a segunda Democracia na América, de 1840, quando Tocqueville aponta que a democracia norte-americana poderia criar seus próprios males, especialmente o da uniformização gerada por uma sociedade de indivíduos isolados em suas vidas privadas e submissos às idéias de uma opinião pública dominadora. No Tocqueville lido por Rodó, estava ausente todo o esforço de valorização das potencialidades da prática comercial e do espírito associativo norteamericanos para gerar atos notáveis e certo espírito de grandeza, mesmo que não de heroísmo. A dimensão tocquevilliana do desaparecimento das grandes emoções públicas reina ali quase exclusivasmente.

Os males que afligiriam a América estariam mais ligados à ameaça de fossilização das sociedades mercantilizadas, aquilo que Tocqueville identificava como a imobilidade "asiática" que ameaçava as sociedades democráticas que não preservassem o estímulo da individualidade. Nesse ponto, surge outro aspecto de sua nostalgia pela cultura heróica, já que a barbárie não aparece necessariamente como a ameaça principal, 
amd sim como uma alternativa até mais notável, pelo menos em intensidade, que o tedioso fim previsto para as sociedades tomadas pelo igualitarismo radical:

Na ausência da barbárie irruptiva que lança suas hordas sobre os faróis da civilização, com heróica e por vezes regeneradora grandeza, a alta cultura das sociedades deve se precaver contra a obra mansa e dissolvente dessas outras hordas pacíficas, talvez polidas, as hordas inevitáveis da vulgaridade. (RODÓ, 1991, p. 56).

O maior pesadelo rodoniano é um mundo de indivíduos como a personagem Homais, de Flaubert, os quais teriam "uma repugnância instintiva em relação ao grande e cujo atributo é a plaina niveladora". (RODÓ, 1991, p. 56). A crítica de Rodó apontava para os perigos do conformismo gerado pelo igualitarismo e para os valores típicos de um mundo disciplinado pelo interesse e regido pela ética da prudência.

\section{Referências Bibliográficas}

BANNISTER, Robert C. Social Darwinism. Science and myth in Anglo-American social thought. Philadelphia: Temple University Press, 1979.

BELLAH, Robert Neelly. The broken covenant. American civil religion in time of trial. Chicago: University of Chicago Press, 1992.

CAWELTI, John G. Apostles of the self-made man. Changing concepts of success in America. Chicago / Londres: The University of Chicago Press, 1972.

DEVES VALDÉS, Eduardo. El pensamiento latinoamericano en el siglo XX. Entre la modernización y la identidad. Buenos Aires: Centro de Investigaciones Diego Barros Arana, 2000.

HIRSCHMAN, Albert O. As paixões e os interesses. Argumentos políticos a favor do capitalismo antes de seu triunfo. São Paulo: Paz e Terra, 1979.

HOWE, Daniel Walker. Making the American self. Jonathan Edwards to Abraham Lincoln. Cambridge; London: Harvard University Press, 1997.

KAHAN, Alan S. Aristocratic liberalism. The social and political thought of Jacob Burckhardt, John Stuart Mill, and Alexis de Tocqueville. New York; Oxford: Oxford University Press, 1992.

MURUCI, Fabio . Nascidos no maravilhoso. O excepcionalismo americano nos escritos de viagem de Domingo Sarmiento e José Martí. Dimensões. Revista de História da UFES, v. $19,2007 . \quad$ Disponível em: https://periodicos.ufes.br/dimensoes/article/view/2457. 
NOBLE, David. The Eternal Adam and the New World Garden. The central myth in the American novel since 1830. New York: George Braziller, 1968.

RODÓ, José Enrique. Obras Completas. Madrid: Aguilar, 1967.

RODÓ, José Enrique. Ariel. Campinas: Editora da UNICAMP, 1991.

SANCHEZ, Luis Alberto. Balance y liquidación del novecientos. Santiago: Ediciones Ercilla, 1941.

SPENCER, Herbert. Herbert Spencer on the Americans and the Americans on Herbert Spencer. YOUMANS, Edward L. (org.). New York: Arno Press, 1973.

TOCQUEVILlE, Alexis de. A Democracia na América. Belo Horizonte: Itatiaia, 1998. 